\title{
Austenitic Stainless Steel Cladding Interface Microstructures Evaluated for Petrochemical Applications
}

\author{
Characterization of martensite and austenite at the interface for \\ dissimilar fusion welds, friction welds, and hot roll bonds between \\ stainless steel and 1018 steel was examined
}

BY N. SWITZNER AND Z. YU

\begin{abstract}
Low-carbon steel was clad with austenitic stainless steel using three different processes: fusion welding, hot roll bonding, and inertia friction welding. Systematic metallurgical characterization was performed for the etching response, microhardness, compositional mixing, constituent phases, and morphology to evaluate their advantages and limitations. The composition across the transition region was used as the input into the Gooch equation for calculation of martensite start temperature to estimate the thickness of the martensite region. The E309L stainless steel fusion weld cladding exhibited a > 100- $\mu \mathrm{m}$-thick, continuous region of interfacial martensite due to partial mixing with the base 1018 steel and subsequent phase transformation during cooling. In addition, the fusion weld exhibited large austenite grains. The combination of a continuous martensite layer and large austenite grains has been demonstrated to be detrimental in claddings for petrochemical applications. In comparison, solid-state joining methods suppressed the formation of martensite to different extents. For instance, hot roll bond cladding of $304 \mathrm{~L}$ stainless steel on low-carbon steel precluded martensite layer formation due to the relatively low amount of total deformation, but the austenite grains were enlarged due to long holding times at an elevated temperature. On the other hand, friction welding produced thin $(\sim 1 \mu \mathrm{m})$ and discontinuous martensite interlayers and thin $(\sim 5 \mu \mathrm{m})$ austenite grains at the dissimilar interface, indicating good potential for cladding applications in petrochemical processing piping and equipment.
\end{abstract}

\section{KEYWORDS}

- Cladding • Fusion Welding • Inertia Friction Welding

- Hot Roll Bonding • Martensite

\section{Introduction}

The corrosiveness of many petroleum reserves as well as the need to process the extracted fluids at high temperatures creates a large and growing demand for steel structures with improved corrosion resistance (Ref. 1). It is often desirable to construct tanks, reactors, and piping from a low-cost metal, such as low-alloy steel, then line the component internally with costlier corrosion resistant (CR) metals, such as stainless steels or nickel alloys (Ref. 1). For instance, stainless steel cladding can be used to prevent sulfidation of low-chromium steel by sour crude (Ref. 2). The global trend is toward an increase in highly acidic (e.g., $\mathrm{H}_{2} \mathrm{~S}$ laden) reserves (Refs. 3, 4). Thus, a concomitant uptick in use of CR lining has occurred and is expected to continue (Ref. 2). For the fatigue, stress, and corrosion mechanisms common to the petroleum industry, a metallurgical bond between the pipe and the CR lining provides longer service life in comparison with a mechanical bond (e.g., by hydraulic expansion [Ref. 4]), although processes to produce a metallurgical bond are generally more costly (Ref. 5).

In this work, metallurgically bonded claddings generated by three different methods were systematically characterized and compared, including two commercial cladding techniques, i.e., fusion cladding and hot roll bonding (HRB), and inertia friction welding (IFW). Fusion cladding is often used to apply CR metal internally to a billet (Ref. 6) prior to extrusion of the bimetal billet to form a seamless pipe (Ref. 7). Hot roll bond cladding is used to bond $C R$ metal to mild steel plate (Ref. 8), then the bimetal sheet is formed into pipe, seam welded, and expanded (Ref. 8). The authors recently proposed modification of the inertia friction process to facilitate its use for advanced cladding applications for petrochemical process piping and appurtenances (Ref. 9). The new solid-state cladding method (Ref. 9) is to apply CR metal internally to a billet by IFW, followed by extruding to form seamless pipe. Potential benefits of this solid-state cladding method include a short processing time, reduced energy consumption, adaptability for a variety of $C R$ alloys (Ref. 9), and reduction of the risk of disbonding associated with a thick and continuous martensite layer. Subsequently, we further introduce these three cladding processes and existing issues.

\section{Fusion Weld Cladding of a Preextrusion Billet}

Fusion cladding of a preextrusion billet is carried out by depositing a 6-100-mm CR clad layer internally to the billet (Ref. 10). After extrusion, a 2-5-mm layer of CR metal re- 

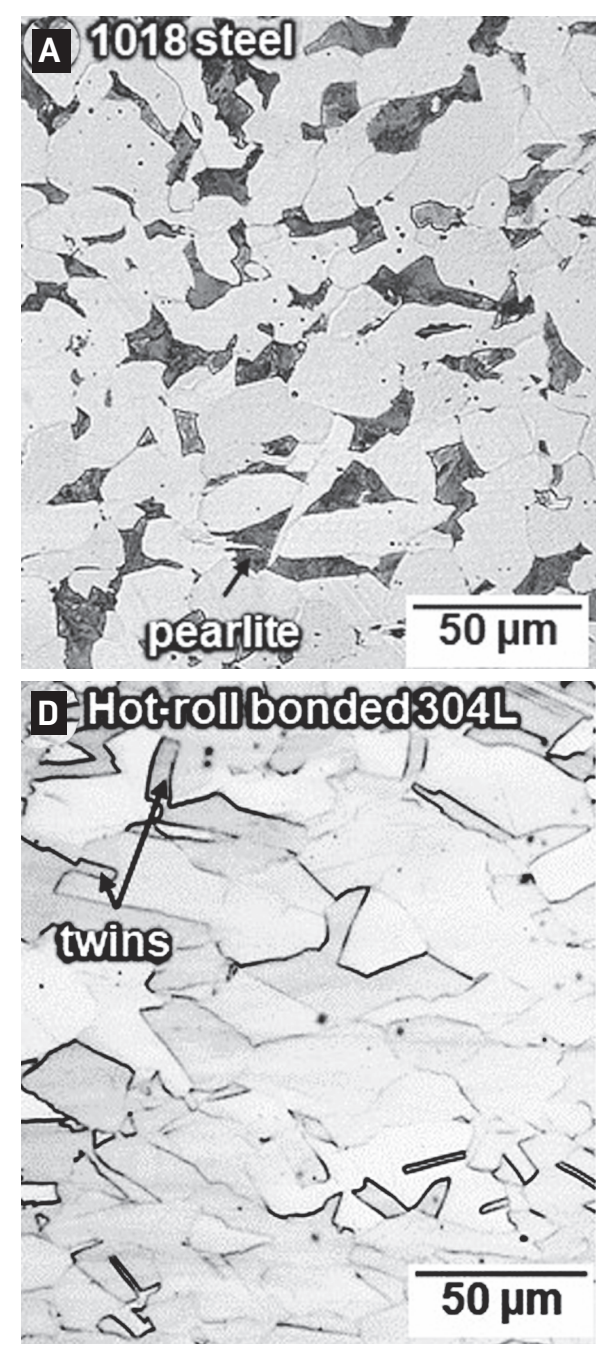

mains internal to $100-500 \mathrm{~mm}$ diameter pipe (with a wall thickness of 10-20 mm) (Ref. 10). Processing issues for fusion CR cladding include the high energy and time requirements (Ref. 10).

Throughput is

low for fusion CR cladding because weld overlay deposition rates are limited (Ref. 10). The peak temperature for fusion welding of AISI type 309L stainless steel is 2000 to $2800 \mathrm{~K}$ (Ref. 11), thus requiring considerable energy to melt and deposit the CR metal.

Metallurgical issues for fusion CR cladding include dilution, interdiffusion, and partitioning of elements during solidification. Effects include disbonding (Refs. 12-14), decar-

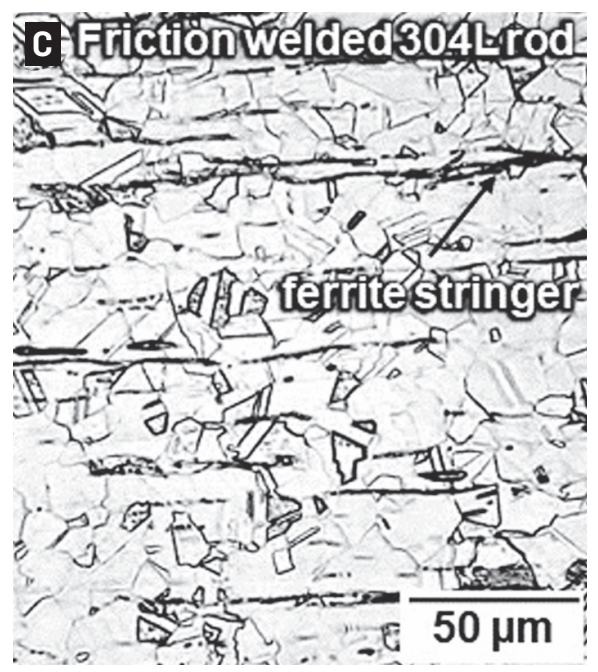

Fig. 1 - Cladding and base steel microstructures: A - Representative 1018 base metal (2\% Nital); B - fusion weld deposit of $309 \mathrm{~L}$ stainless steel (Kallings 2); C - inertia friction welded 304L rod (glyceregia); $D$ - hot roll bonded $304 \mathrm{~L}(\mathrm{HCl})$.

burization and grain coarsening of the base metal (Ref. 15), and formation of hard and soft zones near the interface (Ref. 16). In petroleum refineries, disbonding was reported in the weld cladding compositional transition region (Ref. 17). Interfacial cracking was also a common failure mode for welds of 316 stainless steel to alloy steel subjected to 100 $\mathrm{MPa}$ stress for $1000 \mathrm{~h}$ at $580^{\circ} \mathrm{C}$ (Ref. 18). Two potential causes for cracking in fusion weld claddings include interfacial martensite (Ref. 19) and Type II austenite grain boundary, which will be addressed in detail in the discussion section (Ref. 20).

\section{Inertia Friction Weld Cladding}

This work represents the initial stages of an investigation into the applicability of friction welding for suitability for future novel cladding applications. In IFW, two workpieces are brought together with the controlled application of pressure and rapid rotational motion to produce frictional heat and form a metallurgical bond at the interface (Refs.

21-23). As a solid-state joining process, IFW can lower energy costs and significantly reduce processing time in compar-

Table 1-Compositions of Base Metals and CR Metals

\begin{tabular}{|c|c|c|c|c|c|c|c|c|c|c|}
\hline Fusion Weld Cladding & & $\mathrm{Cr}$ & $\mathrm{Ni}$ & $\mathrm{Mn}$ & Mo & $\mathrm{Si}$ & S & C & $\mathrm{N}$ & $\mathrm{P}$ \\
\hline Base steel & 1018 & 0.16 & 0.10 & 0.79 & 0.03 & 0.24 & 0.03 & 0.17 & - & 0.014 \\
\hline CR wire (typical) & $309 \mathrm{~L}$ & 22.6 & 12.6 & 1.3 & - & 0.9 & - & 0.029 & - & - \\
\hline CR cladding (deposit) & 309L & 20.7 & 10.3 & 1.26 & 0.23 & 0.90 & 0.01 & 0.02 & 0.064 & 0.026 \\
\hline Steel bar & 1018 & 0.12 & 0.07 & 0.66 & 0.02 & 0.22 & 0.017 & 0.16 & 0.007 & 0.013 \\
\hline CR bar & $304 \mathrm{~L}$ & 18.2 & 8.10 & 1.46 & 0.39 & 0.28 & 0.025 & 0.025 & 0.081 & 0.034 \\
\hline Base steel (nominal) & S235JR & - & - & 1.40 & - & - & 0.04 & 0.17 & 0.012 & 0.040 \\
\hline CR cladding type & $304 \mathrm{~L}$ & 18.5 & 10.2 & 1.32 & 0.36 & 0.41 & 0.01 & 0.01 & - & 0.035 \\
\hline
\end{tabular}




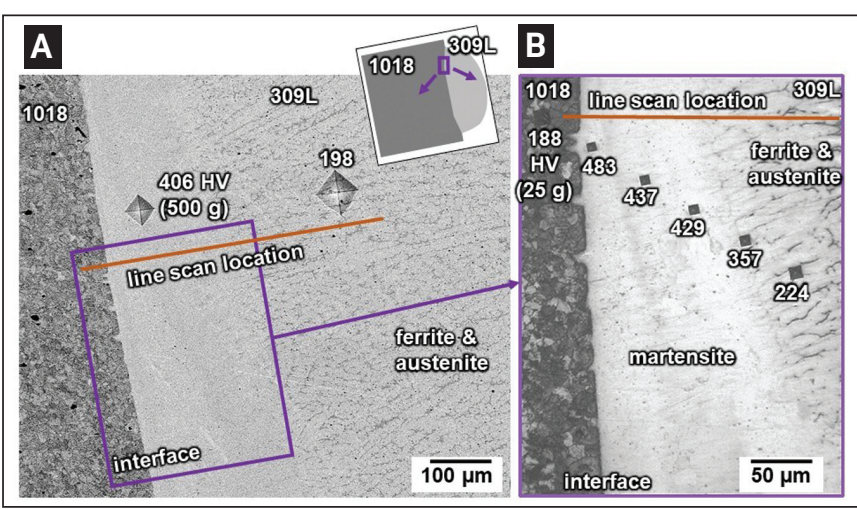

Fig. 2 - Fusion weld cladding interface between the 1018 base metal and the deposit of 309L stainless steel: A - SEM image; B - LOM (2\% Nital and Kallings 2 etch). Note the location of the EDS line scan in Fig. 3.

ison with fusion welding (Ref. 24). Many dissimilar metals can be friction welded (Ref. 25), creating the opportunity to use friction welding for cladding carbon steel with corrosion-resistant alloys. The microstructural characteristics at the bond interface of friction welding clad will be investigated in this study.

\section{Hot Roll Bond Cladding}

HRB clad plates (and subsequently formed pipes) are frequently used in oil and gas production and refining (Ref. 8). Metallurgically relevant steps in production of HRB plate include rolling of both the base metal and CR metal, surface preparation, edge welding, grinding, evacuation, hot rolling, roll leveling, and heat treatment (Ref. 8). More than $90 \%$ of global CR clad plate was reported to be produced by HRB cladding (Ref. 27). Processing issues for HRB cladding can include poor bonding (Ref. 16) and entrainment of inclusions at the interface (Ref. 28). Formation of a fine (less than $\sim 5 \mu \mathrm{m}$ thick) martensite layer has been suspected at the interface based on elemental diffusion and elevated hardness (Ref. 28). After the HRB cladding process, the resulting plate can be formed into CR-lined pipe then longitudinally seam welded (Ref. 8).

\section{Objectives and Material Selection}

In this work, the interfaces formed by the three cladding processes - fusion welding, IFW, and HRB cladding - were compared systematically. Hardness tests, scanning electron microscopy (SEM), energy dispersive spectroscopy (EDS), electron backscatter diffraction (EBSD), and light optical microscopy (LOM) were performed to enable thorough characterizations and comparison of the microstructures (i.e., phase consitituents and their morphology) at the interface. This study aimed to demonstrate the advantages of solidstate cladding, especially the friction cladding process, in controlling interface degradation.

The base plate materials chosen in this work were lowcarbon steels that are commonly used in petrochemical applications. The HRB cladding and inertia friction weld compositions for this study were the corrosion-resistant alloy,

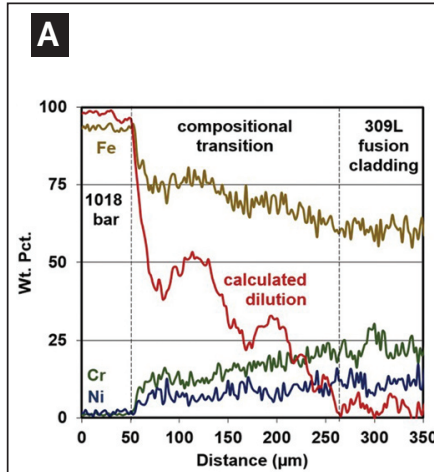

\section{B}

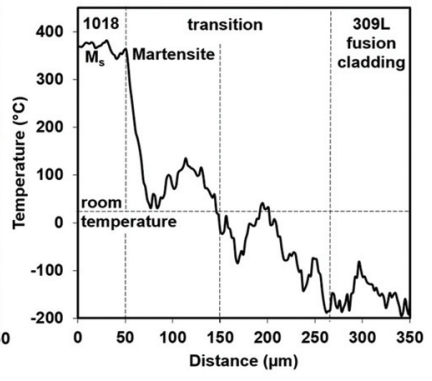

Fig. 3 - Fusion weld cladding interface (A) composition and dilution gradient, and $(B)$ calculated martensite start temperature.

AISI type 304L stainless steel. For the fusion overlay cladding, Type E309L stainless steel was selected because it is often used as a transition layer for cladding carbon steel with austenitic stainless steel (Ref. 27). Near the cladding interface, Type E309L (with elevated $\mathrm{Cr}$ and $\mathrm{Ni}$ ) can result in a composition similar to that of Type 304L stainless steel due to dilution (Refs. 29, 30).

\section{Experimental Methods}

Flux cored arc welding (FCAW) was performed to clad 1.6mm- (1/16-in.-) diameter E309LT0-1 in six passes onto a 38-mm square bar of ASTM A108 grade 1018 steel. Cladding was accomplished using a Miller Axcess ${ }^{\circledR} 450$ operated at $28 \mathrm{~V}$ direct current electrode positive with $148 \mathrm{~mm} / \mathrm{s}$ (350 in./min) wire feed rate. The contact tip to work distance was $16-19 \mathrm{~mm}$ (0.63-0.74 in.), and the shielding cup to work distance was $10-13 \mathrm{~mm}(0.40-0.51 \mathrm{in}$.). Travel speed was $3.8-5.1 \mathrm{~mm} / \mathrm{s}$ (9-12 in./min). The cover gas was $75 \% \mathrm{Ar}$ and $25 \% \mathrm{CO}_{2}$ flowing at $1.2 \mathrm{~m}^{3} / \mathrm{h}\left(40 \mathrm{ft}^{3} / \mathrm{h}\right)$. The calculated average dilution of base metal into the weld metal for the first weld pass was $9 \%$. The compositions of the 1018 steel base metal and as-deposited 309L are shown in Table 1. A transverse sample through the dissimilar interface was extracted for analysis.

For interface evaluation purpose, friction claddings were produced between 25-mm- (1-in.-) diameter round bars of AISI 1018 steel (UNS G10180) and AISI Type 304L stainless steel (UNS S30403). 304L was selected for economic consideration, following the typical hot roll bond cladding practice. The compositions of the materials are given in Table 1 . The 1018 and 304L bars were machined to $100-\mathrm{mm}$ (4-in.) lengths. The faying surfaces were cleaned with isopropyl alcohol to remove any lubricants or contaminants immediately before loading in the IFW equipment. A MTI model 120B inertia friction welding machine was used to produce the welds. The 1018 bar was held stationary, and the 304L bar was rotated. Both bars had $25 \mathrm{~mm}$ (1 in.) of "stick out" (bar exposed beyond the chucks). Processing parameters were similar to handbook nominal values (Ref. 31), with a flywheel inertia of $0.805 \mathrm{~kg} \cdot \mathrm{m}^{2}$, rotation speed of $3100 \mathrm{rpm}$, and axial pressure of $148 \mathrm{MPa}$. A schematic of the friction welding process is available elsewhere (Ref. 31 ). 

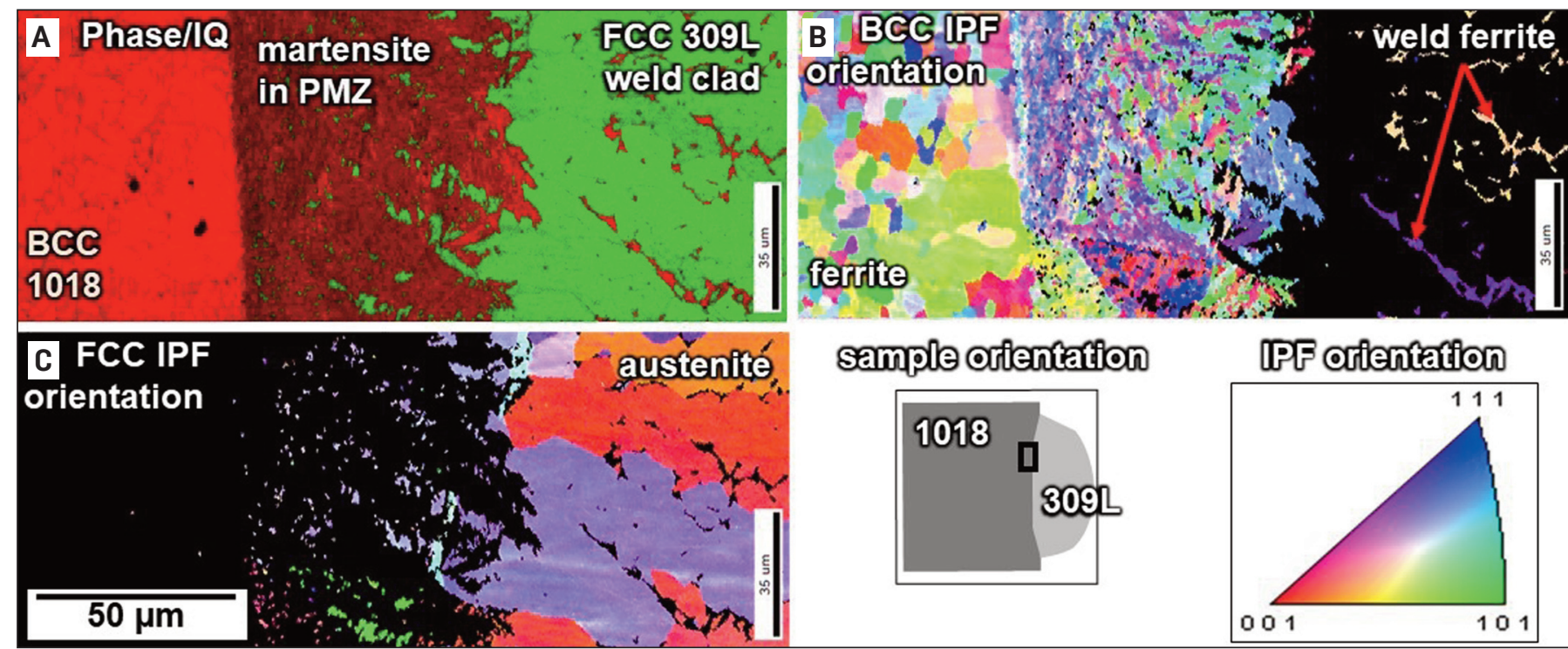

Fig. 4-EBSD at the fusion weld cladding interface: A - Image quality map (shading) overlaid with phase map (color); B - inverse pole figure (IPF) grain orientation map for BCC; $C$ - IPF orientation map for FCC.

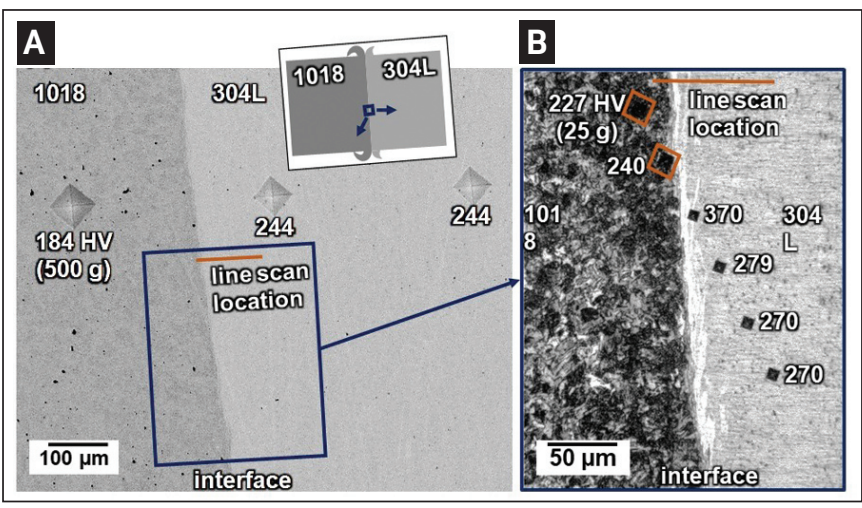

Fig. 5 - Inertia friction weld interface near center between 1018 steel and $304 \mathrm{~L}$ stainless steel: A - SEM image; B - LOM. Note the location of the EDS line scan in Fig. 6 (2\% Nital and Kallings 2 etch).

HRB clad plates with 2 mm of 304L stainless steel on 10mm-thick S235JR steel plate was provided by a commercial supplier. The composition of the cladding material is shown in Table 1. Composition of the S234JR are nominal values taken from EN 10025 (Ref. 32).

Specimens were extracted perpendicular to each interface for characterization. Microhardness testing was performed using a Leco MHT220 hardness tester on surfaces vibratory polished with $0.04-\mu \mathrm{m}$ colloidal silica. Microhardness traces were made using a 500-g load with a dwell time of 12 s. Microhardness of individual phases was determined using a 25-g load (Ref. 33). A FEI Quanta 600i environmental SEM was used to examine the sample interfaces. An EDS line scan was used for compositional analysis. A JEOL JSM-7000F field emission SEM (FESEM) was also used to characterize the bond interfaces with a working distance of $18 \mathrm{~mm}$. EBSD patterns for body centered cubic (BCC) ferrite and face centered cubic (FCC) austenite were collected using an EDAX AMETEK 9424 detector. EBSD data cleanup was performed using TSL-OIM Analysis 7. Inverse pole figure (IPF) maps were generated, with plot grain orientations in the crystallographic coordinate system (Ref. 34). Metallographic characterization using optical microscopy was also performed. Nital (2\%) etchant was used for the mild steel side of each sample. The stainless steel side of the fusion welds and inertia friction welds was etched with Kallings 2, and the HRB sample was etched with pure HCI. Etching took place by manually swabbing one side of the sample with each etchant. Note that this etching method reveals the microstructure of the clad and substrate separately.

\section{Results}

\section{Microstructures of Base Metals and Claddings}

The starting base metal and weld deposit or cladding microstructures are shown in Fig. 1. The base 1018 and S235JR steel microstructures were similar for all cladding methods, thus Fig. 1A provides one representative metallographic image of 1018, exhibiting 20-40 $\mu \mathrm{m}$ ferrite grains and pearlite (dark constituent). The 309L FCA fusion weld deposit microstructure in Fig. 1B consisted of large (> $100 \mu \mathrm{m})$, columnar austenite grains, and vermicular ferrite (Ref. 35). For the inertia friction weld, the microstructure of the 304L bar in Fig. $1 C$ consisted of equiaxed $10-30 \mu \mathrm{m}$ austenite grains and ferrite stringers aligned with the rolling direction. For the HRB cladding, the 304L cladding layer in Fig. 1D consisted of 30-60 $\mu \mathrm{m}$ austenite grains with the presence of twins.

\section{Fusion Cladding Interface Characteristics}

Figure 2 reveals the transition microstructure at the interface for the fusion cladding. In Fig. 2A, 1018 steel was differentiated from the 309L alloy by compositional contrast using the SEM backscattered electron detector. The Vickers hardness measurement closest to the interface produced a relatively high reading of $406 \mathrm{HV}$, but $300 \mu \mathrm{m}$ further into 


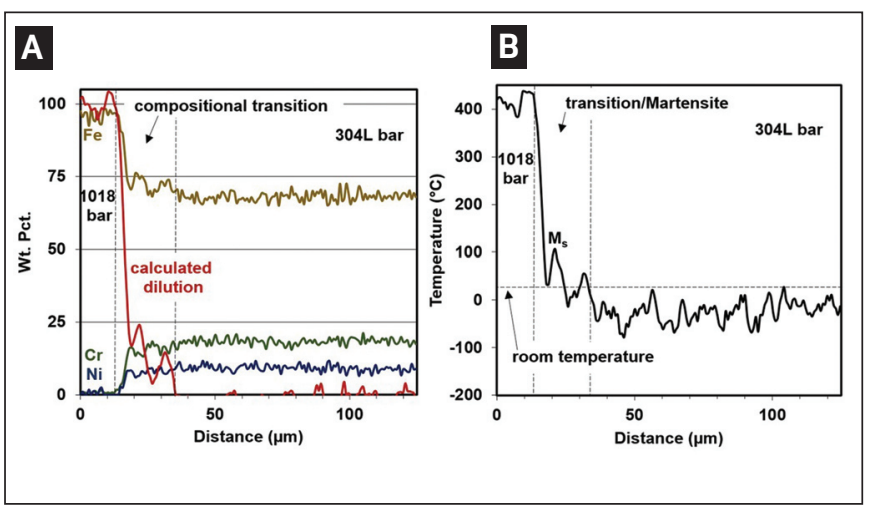

Fig. 6 - Inertia friction weld interface between 1018 steel and 304L stainless steel near center (A) composition and dilution gradient, and $(B)$ calculated martensite start temperature.

the weld deposit, the hardness was much lower, $198 \mathrm{HV}$, as shown in Fig. 2A. The location of the EDS compositional line scan is given in orange, and the location of the LOM image in Fig. 2B is outlined in purple. The microhardness trace across the dissimilar alloy interface using a 25-g load can be found in Fig. 2B. Four hardness readings were greater than $300 \mathrm{HV}$. After etching, it was evident that the region with high hardness was not accentuated by either etchant. This unetched layer varied in thickness, but at the location of the hardness readings it was about $120 \mu \mathrm{m}$ on average.

The EDS compositional line scan for $\mathrm{Fe}, \mathrm{Cr}$, and Ni reveals a transition region from 1018 base metal (left) to 309L filler metal (right) as shown in Fig. 3A. First, there was an initial, abrupt increase to $~ 7 \% \mathrm{Cr}$ by weight and $\sim 4 \% \mathrm{Ni}$ as the scan entered the transition region. Then, over a distance of $\sim 200 \mu \mathrm{m}$, the content of $\mathrm{Cr}$ and Ni gradually increased to $\sim 20 \% \mathrm{Cr}$ and $\sim 10 \% \mathrm{Ni}$, similar to the bulk filler metal (fusion zone) composition.

The dilution, $\mathrm{D}$, across the transition region was calculated per the following difference ratio (Ref. 36):

$\mathrm{D}=\left(\mathrm{C}_{\mathrm{pmz}}-\mathrm{C}_{\mathrm{fm}}\right) /\left(\mathrm{C}_{\mathrm{bm}}-\mathrm{C}_{\mathrm{fm}}\right)$

where $C_{p m z}$ represents the concentration of the selected element in the partially mixed zone (PMZ); $C_{f m}$, the concentration of that same element in the filler metal; and $C_{b m}$, the concentration of that element in the base metal. Average dilution, as shown in Fig. 3A, was calculated by averaging the $\mathrm{Fe}, \mathrm{Cr}$, and Ni dilution, and each concentration reading was averaged over five EDS readings.

Using the dilution calculation, the carbon concentration,

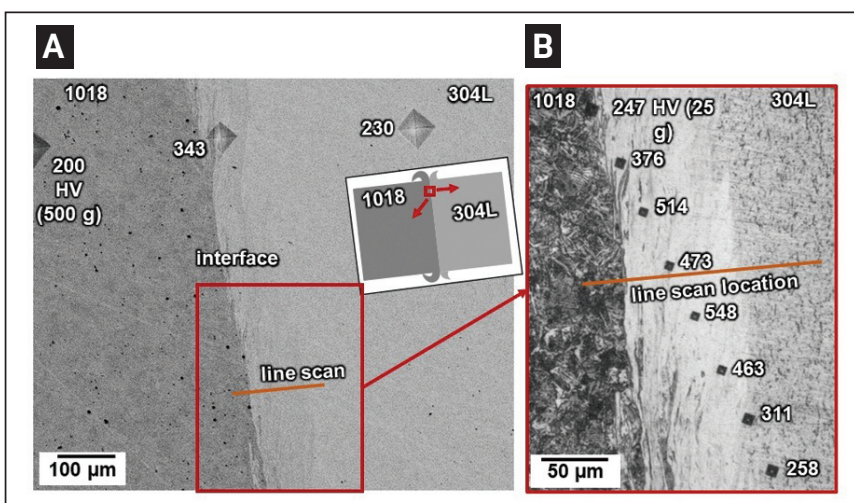

Fig. 7 - Inertia friction weld interface near periphery (A) SEM image, and (B) LOM (2\% Nital and Kallings 2 etch). Note the location of the EDS line scan in Fig. 8.

$C_{C}$, was estimated using the rearrangement (Ref. 36):

$\mathrm{C}_{\mathrm{C}}=\mathrm{DC}_{\mathrm{C}, \mathrm{bm}}+(1-\mathrm{D}) \mathrm{C}_{\mathrm{C}, \mathrm{fm}}$

Using the composition and dilution data, the martensite start temperature, $\mathrm{M}_{\mathrm{s}}\left({ }^{\circ} \mathrm{C}\right)$, was calculated using the empirical expression that Gittos and Gooch developed for martensitic stainless steels of compositions similar to the composition of the interfacial transition region (Ref. 37):

$\mathrm{M}_{\mathrm{s}}=540-\left(497 \mathrm{w}_{\mathrm{C}}+6.3 \mathrm{w}_{\mathrm{Mn}}+36.3 \mathrm{w}_{\mathrm{Ni}}+10.8 \mathrm{w}_{\mathrm{Cr}}+46.6 \mathrm{w}_{\mathrm{Mo}}\right)$

where $\mathrm{w}_{\mathrm{C}}, \mathrm{w}_{\mathrm{Mn}}, \mathrm{w}_{\mathrm{Ni}}, \mathrm{w}_{\mathrm{Cr}}$, and $\mathrm{w}_{\mathrm{Mo}}$ are the compositional weight percent for carbon, manganese, nickel, chromium, and molybdenum, respectively. Note that the calculated $M_{s}$ temperature would not necessarily be accurate in the 1018 steel because the empirical formulation considered only stainless steels (Ref. 36). From Fig. 3B, near the base metal 1018 , the calculated $M_{s}$ temperature begins at $\sim 370^{\circ} \mathrm{C}$, initially drops below room temperature after $\sim 100 \mu \mathrm{m}$, rises above room temperature briefly, and finally drops to below room temperature at a distance of $~ 150 \mu \mathrm{m}$ from the 1018 base metal.

Electron backscatter diffraction analysis at the dissimilar fusion weld cladding interface is summarized in Fig. 4. The leftmost constituent in Fig. 4A was BCC in the 1018 steel heat-affected zone (HAZ). From Fig. 4B, the apparent grain size in the 1018 steel was 5-25 $\mu \mathrm{m}$, which was finer than the base metal. These grains were likely refined by the multiple welding passes. The center constituent of Fig. $4 \mathrm{~A}$ had a

Table 2 - Qualitative Comparison of Martensite Interlayer Width and Austenite Grain Morphology

Martensite Layer

Fusion weld cladding

Inertia friction weld cladding

Hot roll bond cladding
$>100 \mu \mathrm{m}$ thick, continuous

20-80 $\mu \mathrm{m}$ thick, interlayers

Nonexistent or $<1 \mu \mathrm{m}$
Austenite Grains Near Interface

$>70 \mu \mathrm{m}$ thickness and $\sim 40 \mu \mathrm{m}$ width; elongated perpendicular to interface

$\sim 5 \mu \mathrm{m}$ thickness and $\sim 15 \mu \mathrm{m}$ width; elongated parallel to interface

30-60 $\mu \mathrm{m}$, equiaxed 

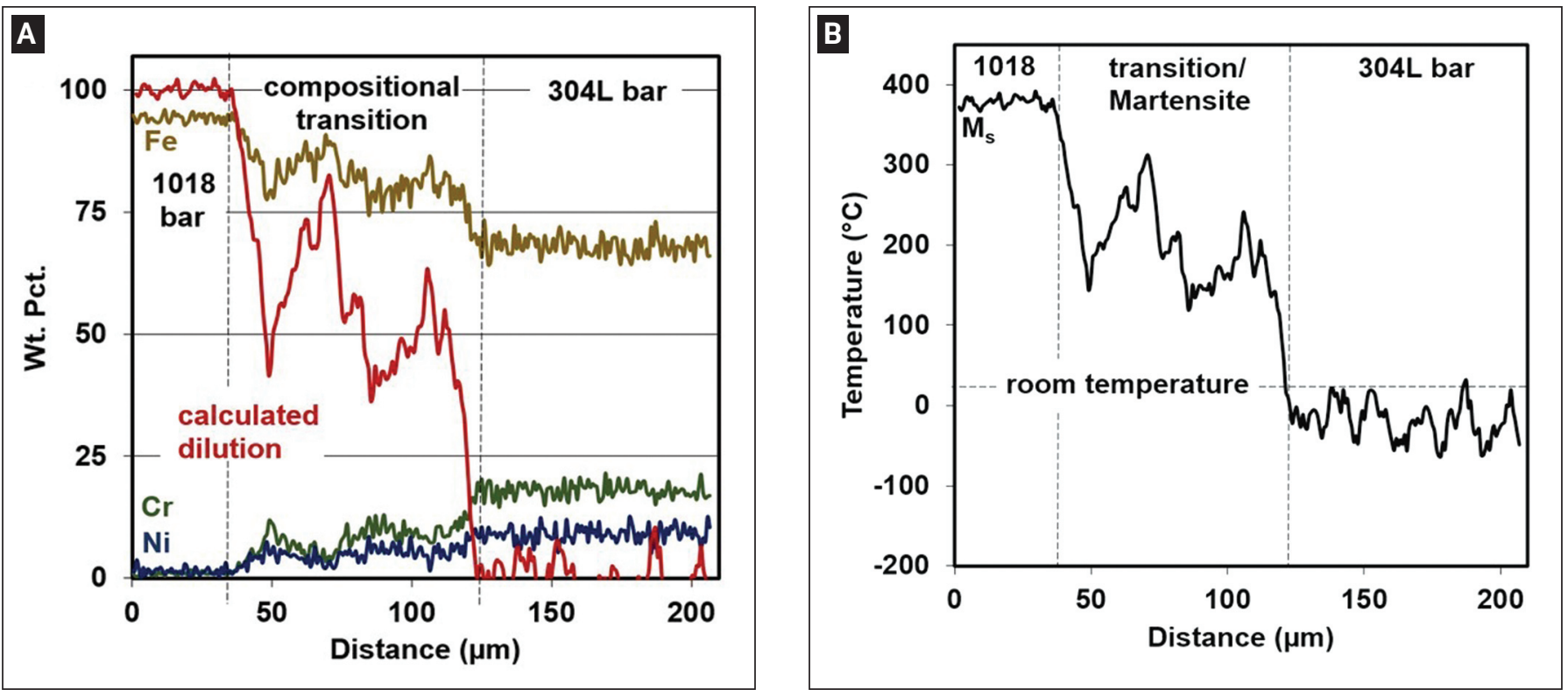

Fig. 8 - Inertia friction weld interface between 1018 steel and $304 \mathrm{~L}$ stainless steel near periphery: A - composition and dilution gradient; $\mathrm{B}$ - calculated martensite start temperature.

darkly shaded image quality and a BCC crystal structure. The IPF orientation map in Fig. 4B showed that the center constituent exhibited very fine grains. The rightmost constituent of Fig. 4A was FCC austenite with large grains as shown in Fig. 4C. The austenite grains were columnar, with intergranular BCC ferrite as identified in Fig. 4B.

\section{Inertia Friction Weld Interface Characteristics}

Characterization of the interfacial transition region was performed on the dissimilar inertia friction butt joint weld cross-section perpendicular to the interface near the meridian. Two locations were chosen for analysis - inner (near center) and outer (near periphery). Figure 5 shows A) a SEM and B) a LOM micrograph of the inner location (near center) at the interface. Figure 5A was produced in SEM compositional mode to enhance the contrast between the 1018 steel and the 304L stainless steel. Three 500-g load Vickers microhardness measurements are shown. The measurement in the 1018 steel HAZ was $184 \mathrm{HV}$, and both measurements in the 304L stainless steel were $244 \mathrm{HV}$ in this location. The location of the EDS compositional line scan is given in orange, and the location of the LOM image is outlined in blue. Figure $5 \mathrm{~B}$ shows a LOM with a microhardness trace across the dissimilar inertia friction weld interface for the inner location (near center). Only one hardness reading of $370 \mathrm{HV}$ is significantly higher than the others. After etching, it is observed that the high hardness reading was in a narrow region that did not respond to either etchant. This unetched layer is $\sim 10 \mu \mathrm{m}$ in thickness at this location near the inertia friction weld center. Figure 6A shows the results of the EDS compositional line scan for $\mathrm{Fe}, \mathrm{Cr}$, and $\mathrm{Ni}$. Consider the compositional transition in Fig. 6A from the 1018 steel bar (left) to the 304L stainless steel bar (right). The increase to 13\% $\mathrm{Cr}$ by weight and $\sim 7 \% \mathrm{Ni}$ occurs within $\sim 7 \mu \mathrm{m}$. Local dilution was estimated using Equation 1, which vanished to zero within a compositional transition region about $20 \mu \mathrm{m}$ in thickness. Note that there were oscillations in the calculated dilution within the compositional transition region. Oscillations in the dilution calculation manifested as variation in the $\mathrm{M}_{\mathrm{s}}$ temperature calculated using Equations 2 and 3 in Fig. 6B. Interestingly, the $\mathrm{M}_{\mathrm{s}}$ temperature descended below room temperature in the middle of the transition region, then rose briefly before finally descending below room temperature within the 304L stainless steel bar. The calculated $\mathrm{M}_{\mathrm{s}}$ temperatures are slightly higher for the 304L bar in Fig. 6B than for the 309L weld deposit in Fig. 3B due to the higher alloy content in the 309L weld deposit.

The SEM image of the outer location (near periphery) for the dissimilar inertia friction weld interface in Fig. 7A shows three 500-g load Vickers microhardness measurements. The hardness measurement at the interface is a relatively high $343 \mathrm{HV}$. The location of the EDS compositional line scan is given in orange, and the location of the LOM image is outlined in red. Figure 7B shows a LOM with a microhardness trace across the dissimilar inertia friction weld interface for the outer location (near periphery). Six hardness readings were $>300 \mathrm{HV}$, including two readings that were $>500 \mathrm{HV}$. After etching, it was observed that the high hardness readings were in a narrow region that did not respond to either etchant. This unetched layer was $\sim 70-80 \mu \mathrm{m}$ in thickness at this specific location near the inertia friction weld periphery. Figure 8A shows the results of the EDS compositional line scan for $\mathrm{Fe}, \mathrm{Cr}$, and Ni. Consider the compositional transition in Fig. 8A from the 1018 steel bar (left) to the 304L stainless steel bar (right). Variation was prominent within the compositional transition region. Dilution vanished to zero within a compositional transition region $\sim 85 \mu \mathrm{m}$ in thickness. The oscillation in the dilution calculation manifested as oscillation in the $\mathrm{M}_{\mathrm{s}}$ temperature calculation in Fig. $8 \mathrm{~B}$ using Equations 2 and 3 . The $\mathrm{M}_{\mathrm{s}}$ temperature did not apparently descend below room temperature in the transition 


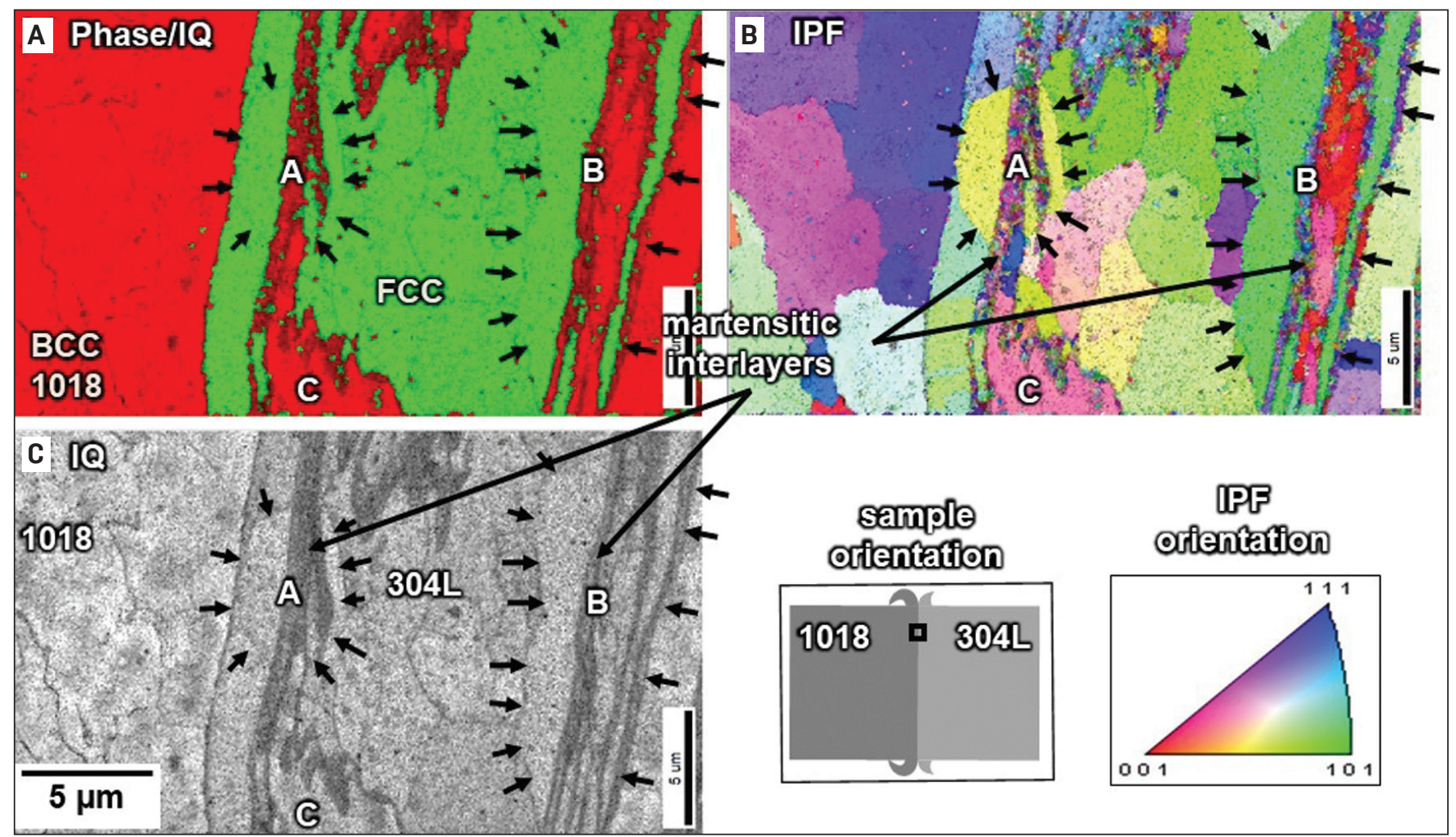

Fig. 9 - EBSD at the interface of the inertia friction weld of 1018 steel to $304 \mathrm{~L}$ stainless steel: A - Phase map with image quality map shading; B - inverse pole figure (IPF) grain orientation map for BCC and FCC; $C$ - image quality map. Small arrows indicate likely prior austenite grain boundaries.

region and finally descended below room temperature within the 304L stainless steel bar.

The EBSD analysis for a location near the periphery of a dissimilar inertia friction butt joint is summarized in Fig. 9. The average confidence index was 0.12 . The cleaned-up image in Fig. 9A distinguishes between FCC and BCC phases. Note that EBSD analysis cannot differentiate BCT and BCC phases. The cleaned-up IPF orientation map in Fig. 9B includes both BCC and FCC phases. The lighter shaded regions in the image quality map, Fig. 9C, correspond with the FCC austenite constituent in Fig. 9A. The image quality map in Fig. 9C was recorded before cleanup, and the dark gray regions indicate low image quality that could be introduced by grain boundaries or martensite (Ref. 38). Austenite was the FCC constituent, and ferrite and martensite were indexed as BCC, although martensite has a BCT structure. The microstructural developments for areas A and B (outlined by arrows) as well as area $C$ will be discussed subsequently in Section 4 .

\section{HRB Cladding Interface}

The interface for the HRB cladding of 304L stainless steel on S235JR steel plate consisted of an abrupt microstructural transition from base metal to cladding as shown in Fig. 10. The SEM image in Fig. 10A was produced in the secondary electron mode. Figure 10B shows a LOM with residual impressions from microhardness indents at the interface. The microhardness was $122 \mathrm{HV}$ in the 1018 steel, $128 \mathrm{HV}$ at the interface, and $221 \mathrm{HV}$ in the 304L stainless steel

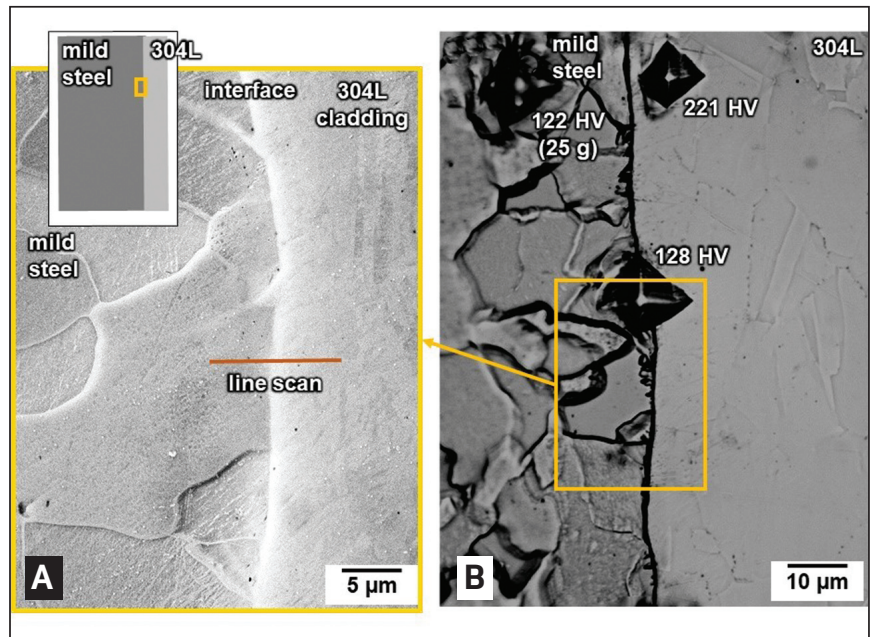

Fig. $10-$ HRB cladding interface between 1018 steel and 304L stainless steel: $A$ - SEM image; B - LOM ( $\mathrm{HCl}$ etch). Note the location of the EDS line scan in Fig. 11.

cladding. There was not a high hardness region that would indicate existence of martensite. Upon examination of 10 $\mathrm{mm}$ of the etched cladding interface, no distinct interfacial region was observed that would indicate existence of martensite.

Similarly, the EDS scan of the interface for the HRB cladding revealed a rapid or stepwise transition as shown in Fig. 11. The orange line in Fig. 10 marks the location of this EDS scan. Note that the scale of the horizontal axis is much 

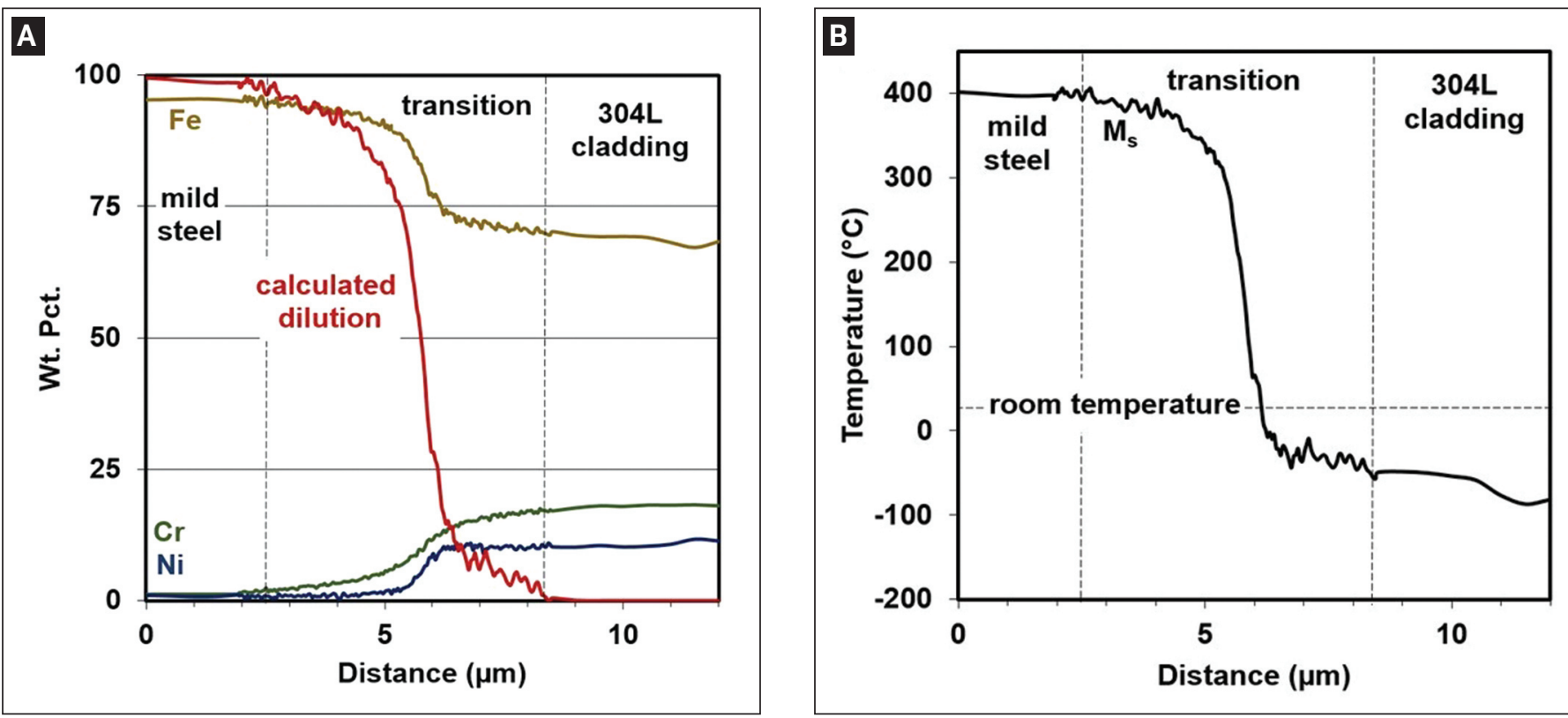

Fig. 11 - HRB cladding interface between 1018 steel and $304 \mathrm{~L}$ stainless steel: A - Composition and dilution gradient; B - calculated martensite start temperature.

smaller than the scale for the EDS scans for the fusion cladding (Fig. 3) and friction weld (Figs. 6 and 8). Though the transition is narrow, the transition behaviors of the $\mathrm{Cr}$ and $\mathrm{Ni}$ are different at the interface. The $\mathrm{Cr}$ transition is slightly more gradual, increasing to $~ 18 \% \mathrm{Cr}$ in a transition region of $\sim 6 \mu \mathrm{m}$ in thickness. However, the Ni transition is more abrupt, increasing to $\sim 10 \%$ in $\sim 2.5 \mu \mathrm{m}$. Figure $11 \mathrm{~B}$ shows that because of the narrow transition from mild steel to $304 \mathrm{~L}$ cladding, the $\mathrm{M}_{\mathrm{s}}$ temperature decreases rapidly from $400^{\circ} \mathrm{C}$ at which martensitic transformation is not likely to occur, to below room temperature, with no significant undulation. It indicates that martensite interlayer formation will be significantly suppressed at this interface, which is in agreement with the EBSD analysis results. The SEM image of the EBSD scan area is shown in Fig. 12A. The image quality map in Fig. 12B was recorded before cleanup. The average confidence index was 0.71 . The phase map in Fig. $12 \mathrm{C}$ distinguishes between FCC and BCC constituents. The IPF orientation maps for FCC and BCC are shown in Fig. 12D and E, respectively. From this analysis, no obvious martensite phase was identified at the interface. It is noted that there appear to be small $(<1 \mu \mathrm{m})$ regions of low-image-quality BCC material at the interface marked by arrows in Fig. 12C.

\section{Discussion}

\section{Detrimental Features in Corrosion Resistant Claddings}

The cladding analysis will be discussed in terms of two types of detrimental features. Firstly, cracking in fusion welds of 316 stainless to alloy steel (Ref. 18) has been linked to a "light etching" (by 2\% Nital) constituent at the dissimilar weld interface, which was identified as martensite (Ref. 39). Gittos showed that the presence of interfacial martensite could increase the risk of hydrogen embrittlement (Refs. 13, 14). In fracture toughness tests, some failures occurred adjacent to the hard zone (Ref. 37). Compositional mixing in the weld region plays the primary role in martensite formation (Ref. 40). A tie line on the Schaeffler diagram is often used to predict the fusion zone composition by accounting for bulk dilution. Any tie line drawn from a mild steel base metal composition to an austenitic stainless steel weld filler metal composition on the Schaeffler diagram traverses the martensite phase stability region. Therefore, martensite is theoretically inevitable near the interface in the compositional transition region (Ref. 19). Indeed, Gittos and Gooch showed that partial mixing near the dissimilar weld interface resulted in "swirls" wherein martensite with hardness up to $\sim 500 \mathrm{HV}$ formed (Ref. 37). Nelson et al. confirmed the presence of martensite in the PMZ of dissimilar welds (Ref. 20). For postweld heat-treated (PWHT) claddings, a large compositional transition region has been linked to interfacial martensite and subsequent hydrogen cracking (Refs. 13, 14).

Secondly, cracking in dissimilar fusion welds of stainless steel to mild steel has been linked to the coarse austenite grains near the dissimilar interface (Refs. 14, 17). Imanaka et al. linked hydrogen disbonding with these coarse austenite grains near the dissimilar weld interface (Ref. 41). Nelson et al. suggested that the austenite grains nearest the interface grew epitaxially, resulting in a high-angle grain boundary called a Type II grain boundary (Ref. 42). This Type II austenite grain boundary is parallel to the weld interface correlated to the location of hydrogen failures reported by Morishige et al. (Ref. 43). Alexandrov et al. indicated that finer grains of austenite adjacent to the dissimilar interface increase the resistance to intergranular cracking due to a more torturous cracking path (Ref. 44).

\section{Fusion Cladding Interface}

This study relied upon multiple tests to confirm the pres- 


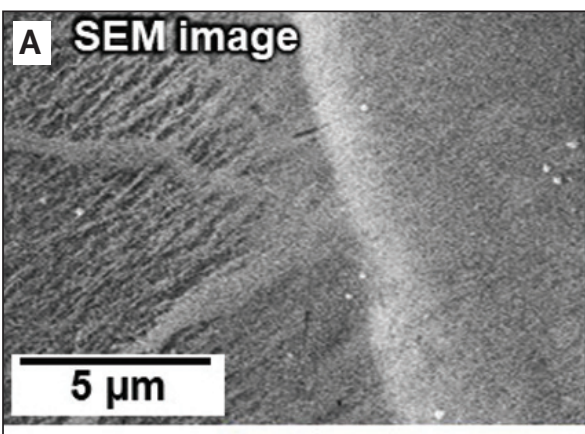

D FCC IPF orientation

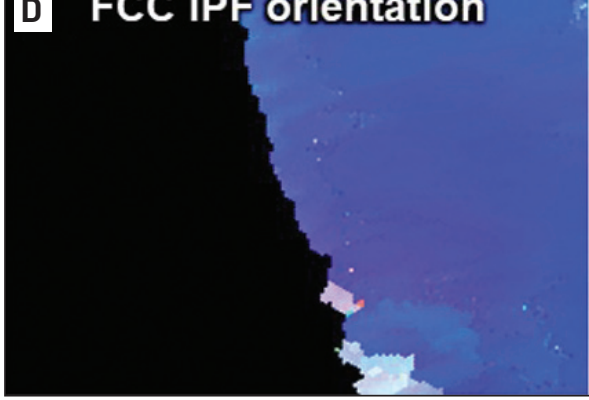

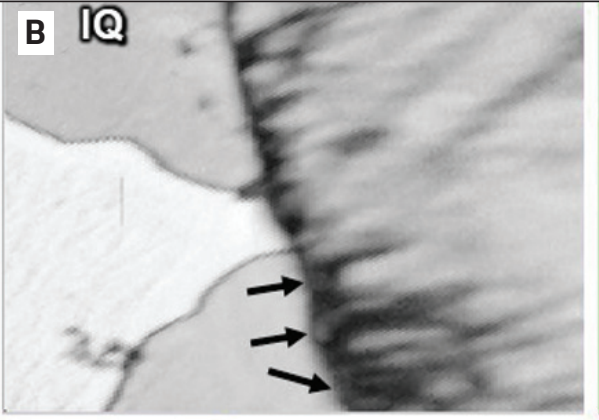

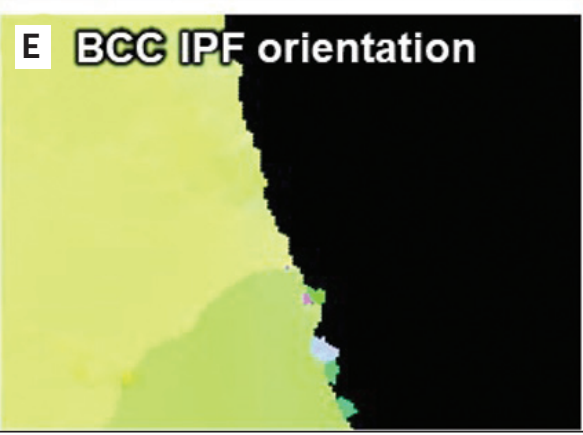

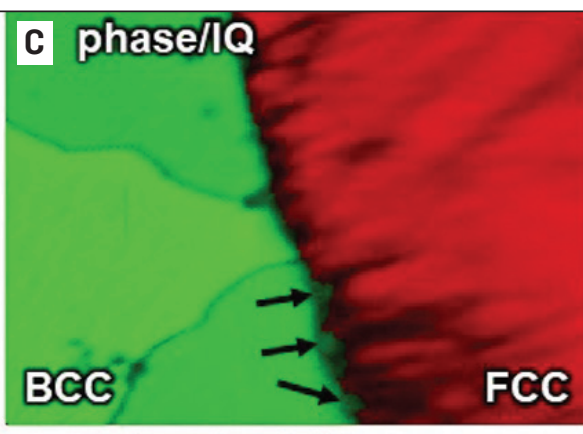

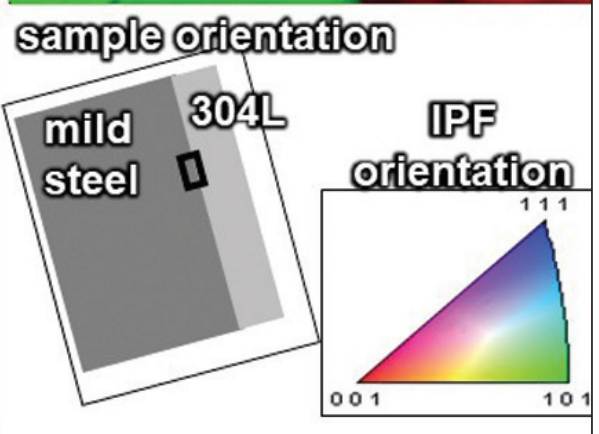

Fig. 12 - EBSD at the interface of the HRB cladding interface between 1018 steel and $304 \mathrm{~L}$ stainless steel: A - SEM image; B image quality map; $C$ - phase map with image quality shading; $D$ - inverse pole figure (IPF) grain orientation map for FCC; $E$ - IPF grain orientation map for BCC.

ence of martensite and estimate the interfacial martensite layer thickness. For the dissimilar fusion weld of stainless steel to low-carbon steel, there are five corroborating indications:

1) A continuous "light etching" constituent is identified at the dissimilar interface in Fig. 2B. A similar light etching constituent at the interface was identified as martensite by Nath for 2.25Cr1Mo fusion clad with Type 316 stainless steel (Ref. 18), and by Chandel and Orr for 2.25Cr1Mo fusion clad with Type 309L stainless steel (Ref. 39).

2) Hardness in the light etching region is much higher than that of either base metal as revealed in Fig. 2A and B. This elevated hardness is characteristic of martensite that forms in dissimilar welds (Ref. 37).

3) Compositional mixing in the PMZ results in the transition zone in the EDS scan in Fig. 3A. Similar to the work of DuPont and Kusko (Ref. 36), the Gooch equation for $M_{s}$ temperature provided an explanation for partial transformation of the transition zone to martensite upon cooling to room temperature (Fig. 3B).

4) Using EBSD, the interfacial region exhibits low image quality as shown in Fig. 4A, which is indicative of martensite (Ref. 38).

5) The interfacial region indexes as ferrite $(B C C)$ by EBSD analysis software as shown in Fig. 4A. Note that EBSD cannot distinguish $\mathrm{BCC}$ ferrite from $\mathrm{BCT}$ martensite since martensite is only slightly tetragonal (Ref. 38).

These five indications demonstrate martensite formation at the fusion cladding interface. The "Type II" austenite grain boundary identified by Nelson et al. (Ref. 20) is not clearly indicated in the present study. However, the individual austenite grains are quite large as shown by Fig. 4C. Also, several EDS scans demonstrate that in the 309L deposit, locations of high $\mathrm{Cr}$ correspond to locations of low $\mathrm{Ni}$ (one ex- ample is Fig. 3A at $\sim 300 \mu \mathrm{m}$ ). This correspondence of high $\mathrm{Cr}$ with low $\mathrm{Ni}$ suggests locations of $\delta$-ferrite along the cores of the primary and secondary dendrite arms that did not transform to austenite (Ref. 35). This vermicular ferrite structure suggests that the 309L weld metal solidified by primary ferrite solidification (Ref. 45).

\section{Inertia Friction Weld Interface}

The same five indications previously described to verify martensite formation for the fusion cladding are also observed for the inertia friction weld: 1) An interfacial "light etching" constituent is identified at the dissimilar interface in Figs. 5B and 7B; 2) the same figures show that hardness in the light etching region is higher than that of either base metal; 3) a compositional transition zone is revealed in the EDS scan in Figs. 6A and 8A; EBSD analysis shows that interlayers in the interfacial region 4) exhibit low image quality; and 5) index as ferrite (BCC) in Fig. 9.

The compositional interlayers, specifically, are interesting, because bulk melting does not occur during friction welding (Ref. 46). The mechanical mixing that occurs during dissimilar IFW caused interlayers of compositional diversity. The layered martensite morphology for the inertia friction welds suggests that martensite transformation occurs in compositionally mixed regions that favored its formation. Whereas for the fusion cladding, compositional mixing in the PMZ occurs in the mushy (solid + liquid) state (Refs. 47, 48), and some compositional segregation occurs during solidification (Ref. 49). Then martensite forms upon cooling. Thus, the martensite in fusion welding exhibits a jagged edge, protruding into the weld deposit (Ref. 19). The EBSD analysis in Fig. 9 was performed at a different location than the EDS scan in Fig. 8, but the compositional transition re- 
gions are likely similar due to their close proximity. In Fig. $8 \mathrm{~B}$ of the inertia friction weld interface, there are large undulations in the predicted $\mathrm{M}_{\mathrm{s}}$. In Fig. 9, thin $(\sim 1 \mu \mathrm{m})$, discontinuous martensite layers were observed, surrounded by small austenite grains. Higher resolution of the EDS analysis would enable a reduction of noise in the data, and may result in the prediction of interlayers of austenite within the martensite layer using the Gooch equation.

Grains A, B, and C in Fig. 9 indicate interesting microstructural developments. Grain A is mostly colored yellow in the IPF map in Fig. 9B, and small arrows outline the likely prior austenite grain boundary. Two multicolored (i.e., indexing for multiple orientations), fine-grained interlayers protrude through grain A and into adjacent grains. These interlayers exhibit low image quality and structure indexed as $\mathrm{BCC}$, indicating that the interlayers are martensitic. Similarly, grain B is mostly colored green in the IPF map in Fig. 9B, and small arrows outline the likely prior austenite grain boundary. There are also martensitic interlayers within grain B. Additionally between some of the low image quality regions are higher image quality regions that index as BCC crystal structure. Whereas the low image quality, BCC-indexed regions indicate martensite (Ref. 38), the high image quality, BCC-indexed regions indicate ferrite. Grain C (colored pink in the IPF map in Fig. 9B) is one example of such a ferrite grain. Grain $C$ exhibits high image quality. Thus, there appear to be martensite and ferrite interlayers within the austenite grains, suggesting that mechanical mixing of the dissimilar alloys caused streaks of compositional differences within FCC austenite grains promoted phase transformation during cooling. BCT products (martensite) formed by an athermal, diffusionless transformation mechanism (Ref. 50) while BCC products (ferrite) formed through a nucleation and growth mechanism (Ref. 51). The nonetching interlayers from LOM may correspond with these interlayered constituents.

The compositional difference between the fusion cladding alloy (E309L) and the inertia friction weld cladding alloy (304L) in this study merit brief comment regarding the effect of the composition on the tendency to form martensite at the interface. Ignoring dilution near the interface, the Type 309L alloy with elevated $\mathrm{Cr}$ and $\mathrm{Ni}$ additions would result in less martensite (Ref. 52). Therefore, one might expect that inertia friction cladding of Type 309L stainless steel would result in a further reduced tendency to form martensite than an inertia friction cladding of Type 304L.

\section{HRB Cladding Interface}

The absence of martensite for the HRB cladding interface can be deduced using the five indications described to verify martensite formation for the fusion cladding. For the HRB cladding, there is no light etching constituent (\# 1) or elevated hardness at the interface (\# 2) in Fig. 10. There is a compositional transition region (\# 3) shown in Fig. 11, but this region is only $\sim 6 \mu \mathrm{m}$ in thickness (for $\mathrm{Cr}$ ). The compositional transition region for the $\mathrm{HRB}$ cladding in this study is half the thickness of that in the study by Xie et al. (Ref. 28), possibly due to differences in heating and cooling rates, and processing times and temperatures. Arrows in Fig. $12 \mathrm{C}$ point out some small grains that exhibit low image quality (\# 4) along with the BCC crystal structure (\# 5) in Fig. 12. It is possible that these $<1$ $\mu \mathrm{m}$ grains are martensitic in nature. Transmission electron microscopy and nanohardness would be suitable techniques to enable confirmation of this assertion.

$\mathrm{HRB}$ cladding is a solid state process, but incorporates high-temperature heating (e.g., $1200^{\circ} \mathrm{C}$ ) for longer times ( $1 \mathrm{~h}$ ) (Ref. 28) than friction welding ( $2 \mathrm{~s}$ for the welds in this study) and slow cooling rates due to batch processing. With the longer times at elevated temperature, the faster diffusion rate (more diffusional spreading) of $\mathrm{Cr}$ as compared to $\mathrm{Ni}$ (Ref. 53) is evident from Fig. 11A. In addition, this extended heating time for HRB claddings is likely the reason for the larger austenite grain size as observed in Fig. 1D. Additionally, HRB cladding is less likely than dissimilar IFW to result in mechanical mixing of the dissimilar metals since there is less motion of one work-piece relative to the second during processing, i.e., little or no mechanical work occurs (Refs. 54, 55).

\section{Base Metal Microstructure}

Although the $\mathrm{M}_{\mathrm{s}}$ temperature for the base low-carbon steel was predicted to be $\sim 400^{\circ} \mathrm{C}$ by the Gooch equation as shown on the left side of Figs. 3, 6, 9, and 11, a martensitic microstructure was not observed in the base steel near the interface. This deviation from the Gooch equation prediction occurs because the Gooch equation applies best to martensitic stainless steels with elevated $\mathrm{Cr}$ and is not necessarily appropriate for low-carbon steel (Ref. 19). Note, however, that the $\mathrm{M}_{\mathrm{s}}$ temperature for a low carbon-steel similar to AISI 1018 actually agrees somewhat with the Gooch $\mathrm{M}_{\mathrm{s}}$ prediction of $\sim 400^{\circ} \mathrm{C}$ (Ref. 56). Thus, the main reason that the low-carbon steel in this test did not form martensite was that the cooling rate was not rapid enough. Cooling from $800^{\circ}$ to $500^{\circ} \mathrm{C}\left(\mathrm{t}_{8-5}\right)$ would have had to take place within $\sim 1 \mathrm{~s}$ to promote the formation of martensite for the low-carbon steel compositions in the present study (Ref. 56). But for all of the processes in the present study, the cooling rate $\left(t_{8-5}\right)$ was much greater than $1 \mathrm{~s}$, thus resulting in a ferrite plus second phase microstructure (Ref. 9).

\section{Comparison of the Cladding Processes}

With regard to cladding applications in petrochemical processes, the two deleterious issues highlighted in the discussion were 1) cracking due to a martensite phase at the fusion cladding interface, and 2) formation of a Type II austenite grain boundary (Ref. 14).

Martensite was identified in the compositional transition region for the fusion weld cladding and the inertia friction weld in this study. However, the thickness and morphology of the martensite layer was different for each process. For the fusion weld cladding, the martensite layer was continuous and relatively thick: generally $>100 \mu \mathrm{m}$. For the inertia friction weld inner and outer locations, respectively, the region of martensite interlayers ranged from 20 to $80 \mu \mathrm{m}$ in thickness. However, the EBSD analysis indicated that the martensite exists in fine, discontinuous interlayers, which is presumably less detrimental to mechanical integrity than a continuous martensite layer. For the HRB cladding only small $(<1 \mu \mathrm{m})$ possible martensitic regions were inferred from the EBSD 
analysis. Thus, the best hydrogen service performance for claddings that undergo PWHT could result from firstly, the $\mathrm{HRB}$ cladding, with its narrow compositional transition region, and secondly the dissimilar inertia friction weld. On the other hand, the fusion weld cladding, with its large compositional transition region, could lead to poor performance. For each of the cladding processes in this study, Table 2 summarizes the qualitative comparison of the microstructural features: martensite interlayer and austenite grain morphology.

For non-PWHT claddings, delayed cracking of rapidly cooled, hydrogen-charged specimens has been linked to hydrogen concentration at the high-angle Type II austenite grain boundaries (Refs. 42, 43). In this study, the austenite grain size near the interface varied greatly between the cladding processes. Firstly, for the fusion weld cladding, the austenite grains were columnar, $>70 \mu \mathrm{m}$ in thickness and $\sim 40 \mu \mathrm{m}$ in width, elongated perpendicular to the interface. For the inertia friction weld cladding, the austenite grains were $\sim 5 \mu \mathrm{m}$ in thickness and $\sim 15 \mu \mathrm{m}$ in width, elongated parallel to interface. The rapid heating and cooling for IFW suppressed significant austenite grain growth. However, for the HRB cladding, the austenite grains were larger $(30-60 \mu \mathrm{m})$ and equiaxed, similar to the grain size of the base stainless steel. Thus, for the case of rapidly cooled hydrogen-charged claddings, where large austenite grain size may cause cladding disbonding, the best performance would be expected from the dissimilar inertia friction weld (with its fine austenite grain size) (Ref. 44).

\section{Conclusions}

In this study, the interfaces of claddings made by three different processes were compared in terms of the microhardness, composition, phase, morphology, and etching response. Five criteria were presented for identification of interfacial martensite for metallurgically bonded austenitic stainless steel claddings. The fusion weld cladding of 1018 steel with 309L stainless steel exhibited a continuous, thick (> $100 \mu \mathrm{m}$ ) region of martensite and large (> $70 \mu \mathrm{m}$ thick) austenite grains due to partial mixing, solidification, and subsequent phase transformation. Dissimilar inertia friction welds of 1018 steel to 304L stainless steel exhibited interspersed, thin $(\sim 1 \mu \mathrm{m})$ and discontinuous martensite interlayers as well as thin $(\sim 5 \mu \mathrm{m})$ austenite grains due to mechanical mixing of the dissimilar compositions and rapid heating and cooling. Although no martensite could be resolved, the presence of fine $(<1 \mu \mathrm{m})$ martensite could not be ruled out for HRB claddings of 304L stainless steel on low-carbon steel. The HRB claddings had large (30-60 $\mu \mathrm{m})$ austenite grains due to extended processing time at elevated temperature. Dissimilar inertia friction welds show good potential for improved interfacial microstructure in cladding applications due to their fine austenite grains and limited presence of discontinuous interlayer martensite.

\section{Acknowledgments}

The American Welding Society (AWS) supported this research with the Graduate Fellowship Grant. Voestalpine provided samples of HRB clad plate.

\section{References}

1. Palmer, A., and King, R. 2004. Subsea Pipeline Engineering. Tulsa, Okla.: PennWell Corp.

2. The Nickel Institute (Report 9021). The role of stainless steels in petroleum refining. pp. 1-57.

3. Duissenov, D. 2013. Production and processing of sour crude and natural gas - Challenges due to increasing stringent regulations. Thesis, Norwegian University of Science and Technology.

4. Sherman, A. 2013. High speed large area fusion cladding. Materials Performance Corrosion Innovation of the Year Awards, pp. $1-24$.

5. Samant, A., Vogli, E., Sherman, A., and Ghildyal, A. 2013. Corrosion resistant alloy cladding for the oil \& gas industry using a high-density infrared fusion cladding process. abakaninc.com/ media/Cladding-Using-High-Density-Infrared-Fusion-CladdingProcess.pdf.

6. SXP: Schultz Xtruded Products. World-class extrusions. sxpusa.com.

7. Neill, D. 2002. Process for Manufacturing Pipes. US Patent No. 6350327.

8. Fischer, C. 2007. Voestalpine Grobblech: Expansion of rollbonding. Stainless Steel World 4: 16-19.

9. Switzner, N. 2017. Friction welding for cladding applications: Processing, microstructure and mechanical properties of inertia friction welds of stainless steel to low carbon steel and evaluation of wrought and welded austenitic stainless steels for cladding. Thesis, Colorado School of Mines.

10. Eagar, T. 1993. Energy sources used for fusion welding. ASM Handbook Vol. 6: Welding, Brazing and Soldering, $8^{\text {th }}$ ed., D. Olson, ed. Materials Park, Ohio: ASM International.

11. Kraus, H. G. 1987. Experimental measurement of thin plate 304 stainless steel GTA weld pool surface temperatures. Welding Journal 66(12): 353-s to 359-s.

12. Wu, Y., Patchett, B. M., and Bicknell, C. 1994. The interfacial microstructure of weld overlay of corrosion resistant alloys. Scripta Metallurgica et Materialia 30(9): 1133-1138. DOI: doi.org/10.1016/ 0956-716X(94)90327-1

13. Gittos, M. F., Robinson, J. L., and Gooch, T. G. 2007. Disbonding of austenitic stainless steel cladding following high temperature hydrogen service. IIW Document Commision IX-2234-072, pp. 1-14.

14. Gittos, M. F. 2008. Resistance of dissimilar joints between steel and nickel alloys to hydrogen assisted cracking (Paper No. 08095). NACE International.

15. Rao, N., Reddy, G., and Nagarjuna, S. 2011. Weld overlay cladding of high strength low alloy steel with austenitic stainless steel - Structure and properties. Materials and Design 32(4): 2496-2506. DOI: 10.1016/j.matdes.2010.10.026

16. Smith, L. 2012. Engineering with Clad Steel. Nickel Institute Technical Series No. 10 064, pp. 1-24.

17. Welding Research Council. 1982. WRC Bulletin 305: Hydrogen embrittlement of bond structure between stainless steel overlay and base metal. pp. 22-39.

18. Nath, B. 1982. Creep rupture and creep crack growth behaviour of transition joints. Welding Technology for Energy Applications, pp. 597-621.

19. Lippold, J. C., and Kotecki, D. J. 2005. Welding Metallurgy and Weldability of Stainless Steels. John Wiley \& Sons.

20. Nelson, T. W., Lippold, J. C., and Mills, M. J. 2000. Nature and evolution of the fusion boundary in ferritic-austenitic dissimilar metal welds - Part 2: On-cooling transformations. Welding Journal 79(10): 267-s to 277-s.

21. Vill, V. 1962. Friction Welding of Metals. New York: American Welding Society.

22. Wang, K., and Lin, W. 1974. Flywheel friction welding re- 
search. Welding Journal 53(6): 233-s to 241-s.

23. Tsang, S. 1993. Friction welding. ASM Handbook Vol. 6: Welding, Brazing, and Soldering. Materials Park, Ohio: ASM International.

24. Vishnu, P., and Sujith, J. 2014. Optimization of friction welding parameters for joining medium carbon steels using response surface methodology. International Journal of Engineering Research and Technology 3(10): 338-345. DOI: 10.1016/ j.jmatprotec.2008.06.030

25. Meyer, A. 2003. Friction hydro pillar processing - Bonding mechanism and properties. Thesis, Von der Gemeinsamen Fakultät für Maschinenbau und Elektrotechnik der Technischen Universität Carolo-Wilhelmina zu Braunschweig als Dissertation angenommene Arbeit.

26. Murti, K., and Sundaresan, S. 1985. Thermal behavior of austenitic-ferritic transition joints made by friction welding. Welding Journal 64(12): 327-s to 334-s.

27. Davis, J. R. 1994. Stainless steel cladding and weld overlays. ASM Specialty Handbook: Stainless Steels.

28. Xie, G., Luo, Z., Wang, G., Li, L., and Wang, G. 2011. Interface characteristic and properties of stainless steel/HSLA steel clad plate by vacuum rolling cladding. Materials Transactions 52(8): 1709-1712. DOI: 10.2320/matertrans.M2011127

29. Ming, H., Zhang, Z., Wang, J., Han, E. H., and Ke, W. 2014. Microstructural characterization of an SA508-309L/308L-316L domestic dissimilar metal welded safe-end joint. Materials Characterization 97: 101-115. DOI: 10.1016/j.matchar.2014.08.023

30. Rajeev, R., Samajdar, I., Raman, R., Harendranath, C. S., and Kale, G. B. 2001. Origin of hard and soft zone formation during cladding of austenitic/duplex stainless steel on plain carbon steel. Materials Science and Technology 17(8): 1005-1011. DOI: doi.org/10.1179/026708301101510852

31. Elmer, J., and Kautz, D. 1993. Fundamentals of friction welding. ASM Handbook Vol. 6: Welding, Brazing and Soldering Materials Park, Ohio: ASM International, pp. 150-155.

32. B2BMetal. 2004. EN 10025-2: European standard for hotrolled structural steel. Part 2 - Technical delivery conditions for non-alloy structural steels.

33. Balmforth, M. C., and Lippold, J. C. 1998. A preliminary ferritic-martensitic stainless steel constitution diagram. Welding Journal 77(1): 1-s to 7-s.

34. AZo Materials. 2015. Generating Orientation Maps to Present EBSD Data. Oxford Instruments, azom.com/article.aspx? ArticleID $=11775$.

35. David, S., Hanzelka, S., and Haltom, C. 1981. Ferrite morphology and variations in ferrite content in austenitic stainless steel welds. Welding Journal 60(4): 63-s to 71-s.

36. DuPont, J. N., and Kusko, C. S. 2007. Technical note: Martensite formation in austenitic/ferritic dissimilar alloy welds. Welding Journal 86(2): 51- to 54-s.

37. Gittos, M. F., and Gooch, T. G. 1992. The interface below stainless steel and nickel-alloy claddings. Welding Journal 71(12) 461-s to 472 -s.

38. Wright, S. I., and Nowell, M. M. 2006. EBSD image quality mapping. Microscopy and Microanalysis 12(1): 72-84. DOI: 10.1017/S1431927606060090

39. Chandel, R. S., and Orr, R. F. 1984. Submerged arc strip overlay welding of 2.25-Cr-1Mo Steel. Welding in Energy-Related Projects 311-321. DOI: 10.1016/B978-0-08-025412-8.50035-8

40. Klueh, R. L., and King, J. F. 1982. Austenitic stainless steel-ferritic steel weld joint failures. Welding Journal 61(9): 302-s to 311-s.
41. Imanaka, T., Shimomura, J., Nakano, S., and Yasuda, K. 1985. Hydrogen attack in Cr-Mo steels and disbonding of austenitic stainless weld overlay. Kawasaki Steel Technical Report 13: 109-119.

42. Nelson, T. W., Lippold, J. C., and Mills, M. J. 1999. Nature and evolution of the fusion boundary in ferritic-austenitic dissimilar weld metals - Part 1: Nucleation and growth. Welding Journal 78(10): 329-s to 337-s.

43. Morishige, N., Kume, R., and Okabayashi, H. 1985. Influence of low-temperature hydrogen degassing on hydrogen-induced disbonding of cladding. Transactions of the Japan Welding Society 16(1): 12-18.

44. Alexandrov, O., Steklov, O., and Alexeev, A. 1993. Use of plasma arc welding process to combat hydrogen metallic disbonding of austenitic stainless steel claddings. Welding Journal 72(11): 506-s to 516-s.

45. David, S. Babu, S. S., and Vitek, J. 2003. Welding: Solidification and microstructure. JOM 6: 1-12. DOI: doi.org/10.1007/ s11837-003-0134-7

46. Hazlett, T. 1967. Fundamentals of friction welding. Welding Journal 46(2): 1-7.

47. Davis, J. 1993. Hardfacing, weld cladding, and dissimilar metal joining. ASM Handbook Vol. 6: Welding, Brazing, and Soldering. Materials Park, Ohio: ASM International, pp. 789-829. DOI: 10.1361/asmhba000

48. Miettinen, J., and Louhenkilpi, S. 1994. Calculation of thermophysical properties of carbon and low alloyed steels for modeling of solidification processes. Metallurgical and Materials Transactions B 25(6): 909-916. DOI: 10.1007/BF02662773

49. DuPont, J. N., Lippold, J. C., and Kiser, S. 2009. Welding Metallurgy and Weldability of Nickel-Base Alloys. Hoboken, N.J.: John Wiley \& Sons.

50. Olson, D. 1985. Prediction of austenitic weld metal microstructure and properties. Welding Journal 64(10): 281-s and 295-s.

51. Elmer, J., Allen, S., and Eagar, T. 1989. Microstructural development during solidification of stainless steel alloys. Metallurgical and Materials Transactions A 20(10): 2117-2131. DOI: 10.1007/ BF02650298

52. Kotecki, D. J. 1999. A martensite boundary on the WRC1992 diagram. Welding Journal 78(5): 180-s to 192-s.

53. Gale, W., and Totemeier, T., eds. 2004. Smithells Metals Reference Book, $8^{\text {th }}$ ed. Elsevier and ASM International. DOI: 10.1016/ B978-075067509-3/50013-0

54. Masuda, S., Nakauchi, I., Tagane, A., Yamawaki, M., and Yako, K. 1988. Rolling characteristics process of cladding plates. ISIJ 28: 470-477.

55. Schmicker, D., Naumenko, K., and Strackeljan, J. 2013. A robust simulation of direct drive friction welding with a modified Carreau fluid constitutive model. Computer Methods in Applied Mechanics and Engineering 265: 186-194. DOI: 10.1016/j.cma.2013. 06.007

56. Vander Voort, G. F. 1991. Atlas of time-temperature diagrams for irons and steels. ASM International, p. 594.

NATHAN SWITZNER and ZHENZHEN YU (zyu@mines.edu) are with the George S. Ansell Department of Metallurgical and Materials Engineering, Colorado School of Mines, Golden, Colo. 